\title{
Optimization Of Hot Strip Finish Rolling Mill Schedule Zhu $\mathrm{Yu}^{1, \mathrm{a}}{ }^{*}$, Cheng Xianmin ${ }^{2, \mathrm{~b}}$ and Wang $\mathrm{TaO}^{3, \mathrm{c}}$ \\ ${ }^{1,2}$ Dalian vocational \& technical college, Liaoning Dalian \\ ${ }^{3}$ China first heavy industries design and research institute, Liaoning Dalian \\ azy-dlvtc@163.com,,cxmtcl@163.com,chaohaiwubian@163.com
}

Keywords: rolling schedule; relative load; plate crown; optimization

\begin{abstract}
Rolling schedule plays a decisive role in rolling of strip steel, and has an important effect on capability of rolling mill. The optimize method of hot strip rolling mill is researched, and the capability of rolling mill is improved effectively, so the quality of the product is also improved.
\end{abstract}

\section{Introduction}

Hot strip rolling mill schedule includes: reduction, speed, and temperature schedule. Reduction schedule determines rolling passes and the reduction per pass. Speed schedule determines the bite speed, through speed and maximum rolling speed without variation in acceleration and deceleration of the motor. Temperature schedule controls the temperature drop of mill house and finish rolling temperature by cooling water flow according start rolling temperature.

Constituting rolling schedule, the following points must be concerned:

(1) Ensuring the shape is good and the plate crown meets the specifications requirement;

(2) Ensuring the yield of rolling mill;

(3) Ensuring the good performance of strip steel.

The constitute method of hot strip rolling schedule is based on how to produce the steel plate which meet the requirements of dimensions, comprehensive properties and microstructure. In this paper, plate crown of steel plate is considered.

\section{Mathematical Model}

The Computing Of Rolling Temperature. Temperature drop of hot strip rolling can be included following four segments [1, 2]:

(1) Radiation temperature drop of strip (steel billet, strip plate) in air when transmitted on roller way or rolling house.

(2)Temperature drop during dephosphorization by high pressure water.

(3)Temperature drop during water spray cooling in rolling house.

(4)Variation in temperature during rolling in rolling house, including: heat loss caused by rolled piece conducting heat to mill roll and roller way; heat increment of system caused by plastic work during rolled piece deformation; heat increment of system caused by friction heat between interface during rolled piece deformation.

In practical temperature prediction model, the effect of rolling speed and rolled piece thickness are considered[3]. Thickness and rolling speed of finished product are introduced into temperature drop equation, as follow:

$$
\Delta t=-\frac{2 \varepsilon \sigma}{\gamma c_{p}} \frac{L_{i}}{h_{n} v_{n}}\left(\frac{T_{i}}{100}\right)^{4} K_{T}
$$

In the equation: $\sigma$ is Stephen Boltzmann constant, is about $4.88 \mathrm{kcal} / \mathrm{m}^{2} \cdot \mathrm{h} \cdot \mathrm{K}^{4}$ or $5.69 \mathrm{~W} /\left(\mathrm{m}^{2} \cdot \mathrm{K}^{4)} ; \varepsilon\right.$ is thermal emittance, is also called blackness $\varepsilon ; \gamma$ is specific gravity of strip steel, $\mathrm{kg} / \mathrm{m}^{3} ; c_{p}$ is specific heat capacity, $c_{p}=1169 \mathrm{~J} /(\mathrm{kg} \bullet \mathrm{k})$ at high temperature; $L_{i}$ is the distance between $i-1$ and $i$ roll house, $\mathrm{m} ; v_{n}$ is the exit velocity of last roll house, $\mathrm{m} / \mathrm{s} ; K_{T}$ is self coefficient related to the thickness and exit velocity of the last roll house. 
Computing Method Of Roll Force. Currently it is generally considered that SIMS equation [4] based on OROWAN deformation zone balance theory is best suited to roll force model of hot strip rolling. On the assumption that the arc of contact surface adhere not slipping, as adhesion, then unit friction $\tau=K / 2$, and there is inhomogeneous deformation in height direction of deformation zone.

Rolling force is as follow:

$$
P=B l_{c}{ }^{\prime} Q_{P} K K_{T} .
$$

In the equation: $P$ is rolling force; $B$ is the width of roll piece; $l_{c}$ is contact arc length of flatten mill roll ; $Q_{p}$ is influence coefficient considering stress caused by friction on contact arc; $K$ is metal deformation resistance, $K=\beta \sigma, \mathrm{MP}_{\alpha} ; K_{T}$ is coefficient of back and forth tensile stress influence to roll force.[5,6]

Equation of external friction stress conditional coefficient is:

$$
\begin{gathered}
Q_{p}=\sqrt{\frac{1-\varepsilon}{\varepsilon}}\left[\frac{1}{2} \sqrt{\frac{R}{h}} \ln \frac{1}{\varepsilon}-\sqrt{\frac{R}{h}} \ln \frac{h_{r}}{h}+\frac{\pi}{2} \arctan \sqrt{\frac{\varepsilon}{1-\varepsilon}}-\frac{\pi}{4}+\frac{\tau_{b}}{K}-\sqrt{\frac{R}{\Delta h}}\left(\frac{\tau_{b}}{K}-\frac{\tau_{f}}{K}\right) \gamma\right] . \\
\gamma=\sqrt{\frac{h}{R}} \tan \left[\frac{1}{2} \arctan \sqrt{\frac{\varepsilon}{1-\varepsilon}}+\frac{\pi}{8} \ln (1-\varepsilon) \sqrt{\frac{h}{R}}+\frac{1}{2} \sqrt{\frac{h}{R}}\left(\frac{\tau_{b}}{K}-\frac{\tau_{f}}{K}\right)\right] .
\end{gathered}
$$

In the equation, $\gamma$ is neutral angle; $\tau_{f}$ is forth tensile stress; $\tau_{b}$ is back tensile stress; $\varepsilon$ is screw down ratio, $\varepsilon=\Delta h / h_{0}, h_{0}$ is entrance thickness, $h$ is exit thickness; $R$ is radius of mill roll.

\section{Construction Of Roll Schedule Optimization Model}

Objective function is mathematical relationship between design variable and optimization objective. In order to determine a set of design variables to make objective function reach extreme, objective function is established.

(1) Equal relative load objective function (uniform distribution to every major motor)

$$
F_{1}=\sum_{i=1}^{n}\left(\lambda_{i}-\lambda\right)^{2} .
$$

In which $\quad \lambda_{i}=\frac{N_{i}}{N_{i}{ }^{\prime}}, \lambda=\frac{\sum_{i=1}^{n} N_{i}}{\sum_{i=1}^{n} N_{i}{ }^{\prime}}, \quad n$-roll pass number(the number of mill house); $N_{i}$-rated power of $i$ major motor.

(2) Objective function of plate crown

$$
F_{2}=\sum_{i=n-1}^{n}\left(C_{i}-C_{0 i}\right)^{2}
$$

In which, $C_{i}$ - the plate crown of i roll pass; $C_{0 i}$-the plate crown of i objective roll pass. Every mill house must meet the constraint condition of roll force, roll torque and motor power. Flow diagram of optimization computation is shown in the Figure 1. 


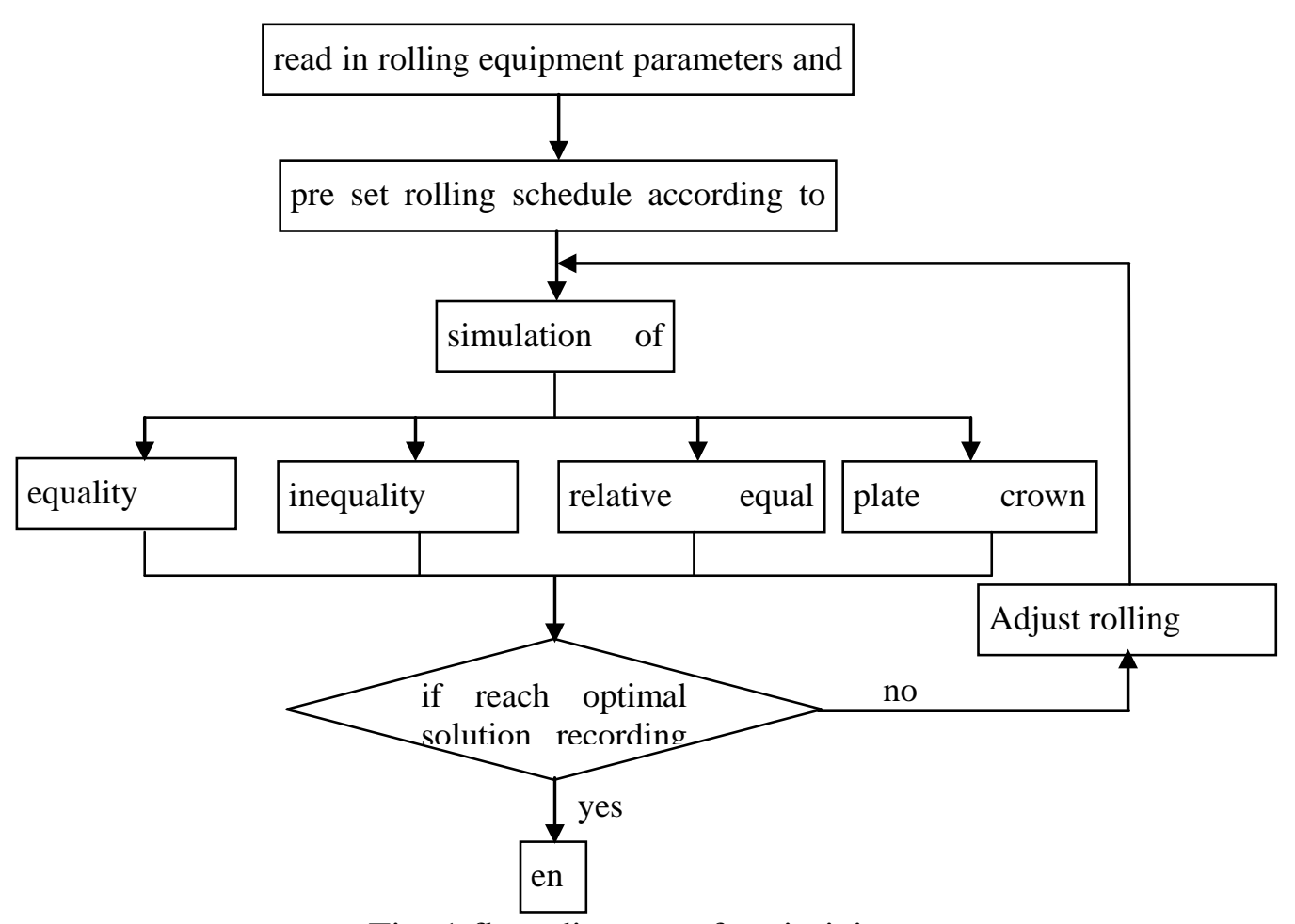

Fig. 1 flow diagram of optimizing

\section{Example Computation And Analysis}

In order to prove the optimizing effect of the model, optimization computation is carried on based on the 2050 hot rolling equipment. The material of rolled piece is Q215, width of rolled piece is $1011 \mathrm{~mm}$, thickness of middle of rolled piece is $45.35 \mathrm{~mm}$, entry plate crown is $345 \mu \mathrm{m}$, and comparison of the rolling schedule is showed in Table 1.

Table 1 comparison of before and after optimization

\begin{tabular}{c|c|c|c|c|c|c|c|c}
\hline \multicolumn{2}{c|}{ mill house } & F1 & F2 & F3 & F4 & F5 & F6 & F7 \\
\hline \multirow{2}{*}{$\begin{array}{c}\text { before } \\
\text { optimizati } \\
\text { on }\end{array}$} & $\begin{array}{c}\text { exit } \\
\text { thickness/mm }\end{array}$ & 29.35 & 18.16 & 13.01 & 9.46 & 6.98 & 5.76 & 5.08 \\
\cline { 2 - 9 } & $\begin{array}{c}\text { screw down } \\
\text { ratio/\% }\end{array}$ & 35.28 & 38.13 & 28.36 & 27.29 & 26.22 & 17.48 & 11.81 \\
\hline $\begin{array}{c}\text { after } \\
\text { optimizati } \\
\text { on }\end{array}$ & $\begin{array}{c}\text { exit } \\
\text { thickness/mm }\end{array}$ & 26.12 & 15.09 & 10.36 & 7.83 & 6.55 & 5.68 & 5.08 \\
\cline { 2 - 10 } & $\begin{array}{c}\text { screw down ratio } \\
\text { /\% }\end{array}$ & 42.23 & 31.35 & 24.42 & 16.35 & 13.28 & 10.56 & 42.23 \\
\hline
\end{tabular}

Fig. 2 shows rolling force and rolling power of before and after optimization comparison. We can conclude from Fig.2 that rolling force increases after optimization in the preceding passes, but induces in last few passes. This corresponds to screw down ratio. Lower screw ratio of the last few passes is benefit to plate shape and control of it. We also can conclude from Fig.2 that before optimization rolling power in the forth pass is larger than that in the preceding passes, but allowable power in the forth mill house is lower than that in preceding house. The fluctuation of power is little, so it confirms to the principle of uniform distribution. 


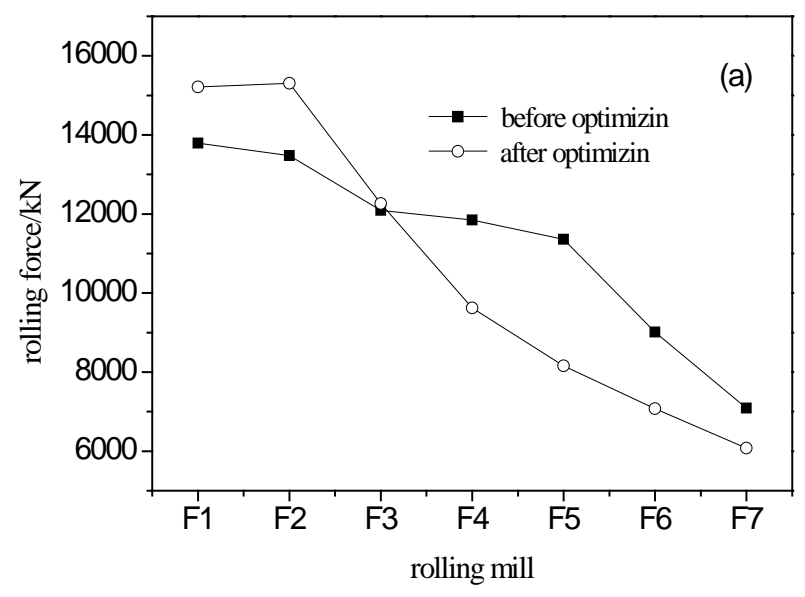

a) rolling force

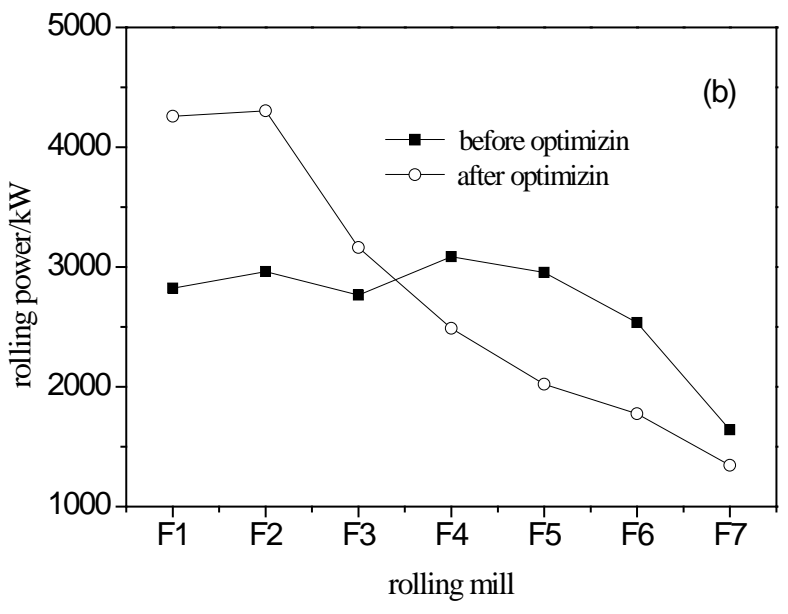

b) rolling power

Fig. 2 rolling force and rolling power of before and after optimization comparison

Fig. 3 shows the plate thickness of before and after optimization comparison. We can conclude from Fig. 3 that plate crown is improved obviously after optimization.

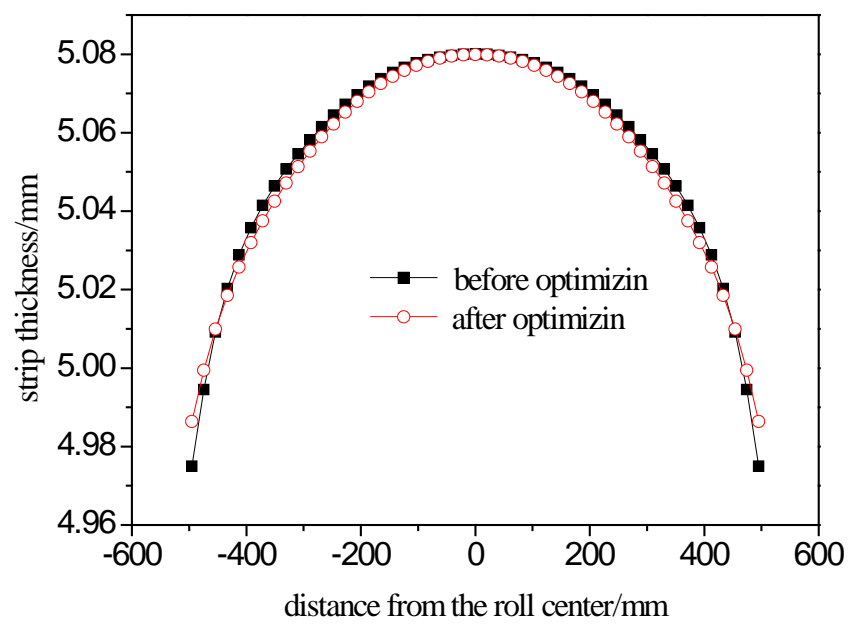

Fig.3 exit computing of last roll house before and after optimization comparison

\section{Conclusions}

Hot strip rolling mill schedule has great influences on the quantities and quality of product. Considering relative equal load and plate crown of product when constituting rolling schedule, is benefit for maximum capability of rolling mill, also can make plate shape better and improve quality of product.

\section{References}

[1] LiHaiJun, ShiLiJun and WangGuoDong: Temperature Model of Hot Strip Mills in Tandem and Its Self-Learning Strategy. Journal of Northeastern University. 2009, 30(5):369-372.

[2] GongChangBao: Temperature Model and Its Application in Hot Strip Rolling. Steel Rolling, 2004,3:34-37.

[3] LiuYan, SunYiKang and GuanKeZhi: On Temperature Model for Finishing Stands in Hot Strip Mill of WuHan Iron and Steel CO., IRON AND STEEL, 2004,3:34-37.

[4] SunYiKang: The Model of Hot Strip Mill and Control. Beijing: Metallurgical Industry Press, 2007:38-44. 
[5] ] Wang Ying Rui , Yuan Jian Guang and Liu Hong Mi: Shape Control Simulation on 4-High CVC Mill[J]. Journal of Iron and Steel Research(International). 2005(02).

[6] Cao Jian Guo, Liu Si Jia and Zhang Jie: ASR work roll shifting strategy for schedule-free rolling in hot wide strip mills. Journal of Materials. 2011. 